\title{
Aromatic Hydrocarbons as Indicators of Maturation and Source: Correlative Geochemical Evaluation of Commingled Niger Delta Crude Oils
}

\author{
Okoroh NC, Onyema MO* and Osuji LC
}

Petroleum and Environmental Geochemistry Research Group, Department of Pure and Industrial Chemistry, University of Port Harcourt, Nigeria

*Corresponding author: Mark 0 Onyema, Petroleum and Environmental Geochemistry Research Group, Department of Pure and Industrial Chemistry, University of Port Harcourt, Choba, Rivers State, Nigeria, Tel: +234 803041 5230; Email: onyemark@yahoo.com

\section{Research Article \\ Volume 4 Issue 2}

Received Date: February 27, 2020

Published Date: April 13, 2020

DOI: $10.23880 /$ ppej-16000218

\section{Abstract}

Two Niger Delta crude oils from Rivers and Delta States (samples A and F) and their compositional mixtures (samples B, C, D and E) where evaluated using a range of geochemical parameters derived from aromatic hydrocarbons and aromatic sulphur compounds to determine their source and maturity. The relative distribution of various plant markers in crude oil samples $\mathrm{A}$ and $\mathrm{F}$ which were retained in their compositional mixes suggests the contribution of angiosperm higher plants and coniferous higher plants to the source rocks that generated the crude oils. The various maturity parameters computed for the oil samples revealed that both the Rivers and Delta crude oils lie in the high maturity state with sample F significantly more matured than sample A. All alkynaphthalene maturity parameters suggested a peak to late oil generation window for the crude oil samples except the methyl naphthalene ratio (MNR) whose maturity sequence lacks sufficient variation to distinguish maturity differences in the crude oil samples. The maturity characters of TNR-1 and TNR-2 (trimethylnaphthalene ratio) showed a strong correlation between the individual crude oil samples and their mixtures. However, all the other maturity parameters showed moderate or weak correlation between the individual crude oil samples and their mixtures.

Keywords: Aromatic hydrocarbons; Maturity; Source; Commingling; Niger Delta

\section{Introduction}

Crude oil consists of a wide range of hydrocarbons that range from saturates, aromatics and nitrogen, sulfur or oxygen (N, S, O) compounds. Embedded within these hydrocarbon compounds are information on the maturity and organic matter source which formed the crude oil [13]. Aromatic hydrocarbons found in crude oils are useful as maturity and source indicators in basin analysis and have been found, in some cases, to be more reliable than the aliphatic biomarkers [4,5]. They are more sensitive to maturity differences in the mid to late parts of the oil generation window [6]. Aromatic sulphur compounds have also demonstrated to be very important in evaluating the maturity of crude oils and source rocks [7-9]. Many of the aliphatic biomarker maturity parameters are reported to reach equilibrium before the main stage of oil window and in some cases show inversion at high maturity levels. As such, they are not effective maturity indicators [4].

Aromatic hydrocarbons are resistant to biodegradation and can span a wide range of thermal maturities under elevated temperatures. These indicators respond to an increase in thermal stress with a predictable alkylation progression of a given parent compound or a shift in the isomer distribution of the alkyl-aromatic homologues towards thermally more stable isomers. The concentrations of the thermodynamically least stable isomers $(\alpha)$ are compared with the thermodynamically more stable isomers $(\beta)$. The principle behind this is that the methyl group shifts from $\alpha$ - to $\beta$-position with increase in thermal maturity [10]. A number of maturity parameters have been developed based on the distributions of the polycyclic aromatic compounds. In this study therefore, the distributions of alkyl naphthalenes, 


\section{Petroleum \& Petrochemical Engineering Journal}

biphenyls, phenanthrenes and aromatic sulphur compounds (thiophenes) were applied to determine the maturity and source of two Niger Delta crude oils as well as the trends exhibited by these aromatic geochemical compounds in their compositional mixes.

\section{Materials and Method}

\section{Study Area}

The Niger Delta region is one of Nigeria's five sedimentary basins where oil is produced. It is an extremely prolific hydrocarbon province situated in Southern Nigeria between longitude $5^{\circ}-9^{\circ} \mathrm{E}$ and latitude $4^{\circ}-6^{\circ} \mathrm{N}$ on the West African continental margin, at the apex of the Gulf of Guinea $[11,12]$. Nine (9) states namely: Ondo, Edo, Delta, Imo, Abia, Bayelsa, Rivers, Akwa-Ibom and Cross-River constitute the oil producing Niger Delta region of Southern Nigeria.

\section{Samples}

Crude oil samples used for the study were obtained from two states in the Niger Delta region namely: Rivers and Delta states. The crude oil samples were collected from two producing oil wells in the states by field technicians with the permission of the Department of Petroleum Resources (DPR) and labelled samples A and F respectively. Mixtures of samples $A$ and $F$ were made at different composition to obtain samples B (4:1), C (3:2), D (2:3) and E (1:4).

\section{Crude Oil Fractionation}

$50 \mathrm{mg}$ of each crude oil sample was weighed into labelled centrifuge tube and excess pentane added to precipitate the asphaltenes. The samples were allowed to stand for four hours and transferred into a fischer centrifuge set at 1,500 rpm for thirty minutes [13]. The pentane soluble fraction was decanted, concentrated and introduced into a glass chromatographic column $(30 \mathrm{~cm} \times 1 \mathrm{~cm})$ stuffed with glass wool at the bottom and packed with activated silica gel. $n$-Hexane was poured into the packed column to elute the saturates, dichloromethane poured to elute the aromatics and dichloromethane/methanol (1:1) mixture poured to elute the resins. The eluents were collected into pre-weighed vials and the solvents evapourated to dryness under a gentle stream of nitrogen at $40^{\circ} \mathrm{C}$.

\section{Gas Chromatography-Mass Spectrometry (GC- MS) Analysis}

Detailed analysis of the aromatic fractions was facilitated by Agilent 7820A gas chromatography (GC) system fitted to a fused silica capillary column $(30 \mathrm{~m} \times 0.25 \mu \mathrm{m})$ and equipped with an Agilent 5975 series mass selective detector (MSD). One microlitre $(1 \mu \mathrm{L})$ of the aromatic component of each fractionated oil sample was injected into the GC capillary column with the aid of a G4513A automatic liquid sampler (ALS) using a split ratio mode of 100:1. The GC oven was initially set at $100^{\circ} \mathrm{C}$ for $5 \mathrm{~min}$, programmed to $320^{\circ} \mathrm{C}$ at $3{ }^{\circ} \mathrm{C}$ $/ \mathrm{min}$, with a final holding time of $25 \mathrm{~min}$. The temperature of feed ports is fixed at $300{ }^{\circ} \mathrm{C}$. The MS was operated with an ion source temperature of $320^{\circ} \mathrm{C}$, and an ionization energy of $70 \mathrm{eV}$. Peak identification was by comparison with related literature. Quantification was acquired by area integration of each identified peak which was processed by Chemstation OPEN LAB CDS software.

\section{Results and Discussion}

GC-MS analysis identified aromatic hydrocarbons in all the crude oil samples. The identified aromatic hydrocarbons include $\mathrm{C}_{0}-\mathrm{C}_{2}$ biphenyls (m/z 154, 168 and 182), $\mathrm{C}_{0}-\mathrm{C}_{4}$ naphthalenes $\left(\mathrm{m} / \mathrm{z} 128,142,156,170\right.$ and 184), $\mathrm{C}_{0}-\mathrm{C}_{3}$ dibenzothiophenes $\left(\mathrm{m} / \mathrm{z} 184,198,212\right.$ and 226) and $\mathrm{C}_{0}$ - $\mathrm{C}_{4}$ phenanthrenes (m/z 178, 192, 206, 220 and 234). Representative mass fragmentograms of the identified aromatic hydrocarbons are presented in Figures 1-4 and their names listed in Table 1. From these a total of 98 aromatic hydrocarbon compounds were selected and used for analysis of the source origin and maturity of the two Niger Delta crude oil samples as well as the trend they exhibit in their compositional mixes.

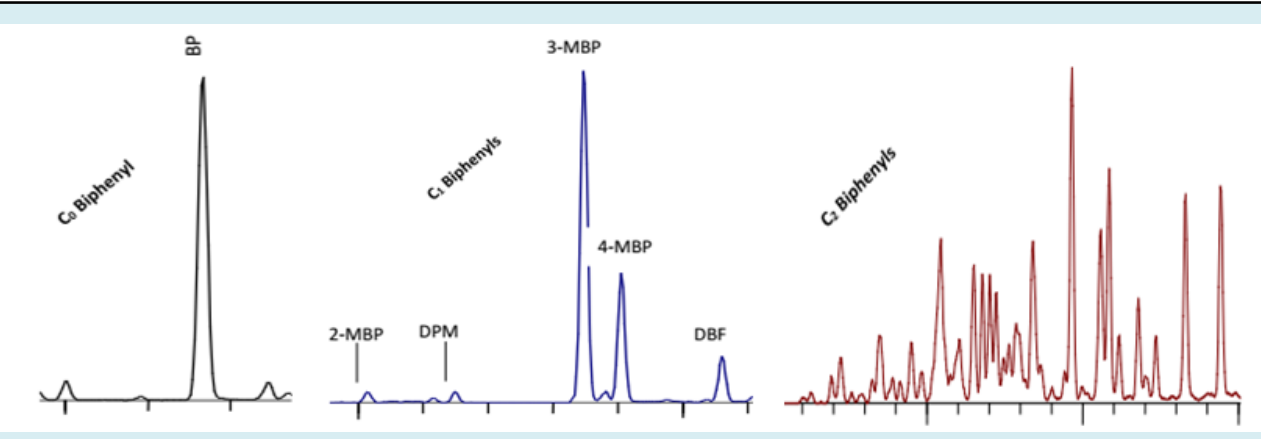

Figure 1: Representative mass fragmentograms showing the distribution of $\mathrm{C}_{0}-\mathrm{C}_{2}$ biphenyls in the sample crude oil (B) at $\mathrm{m} / \mathrm{z}$ 154,168 and 182. 


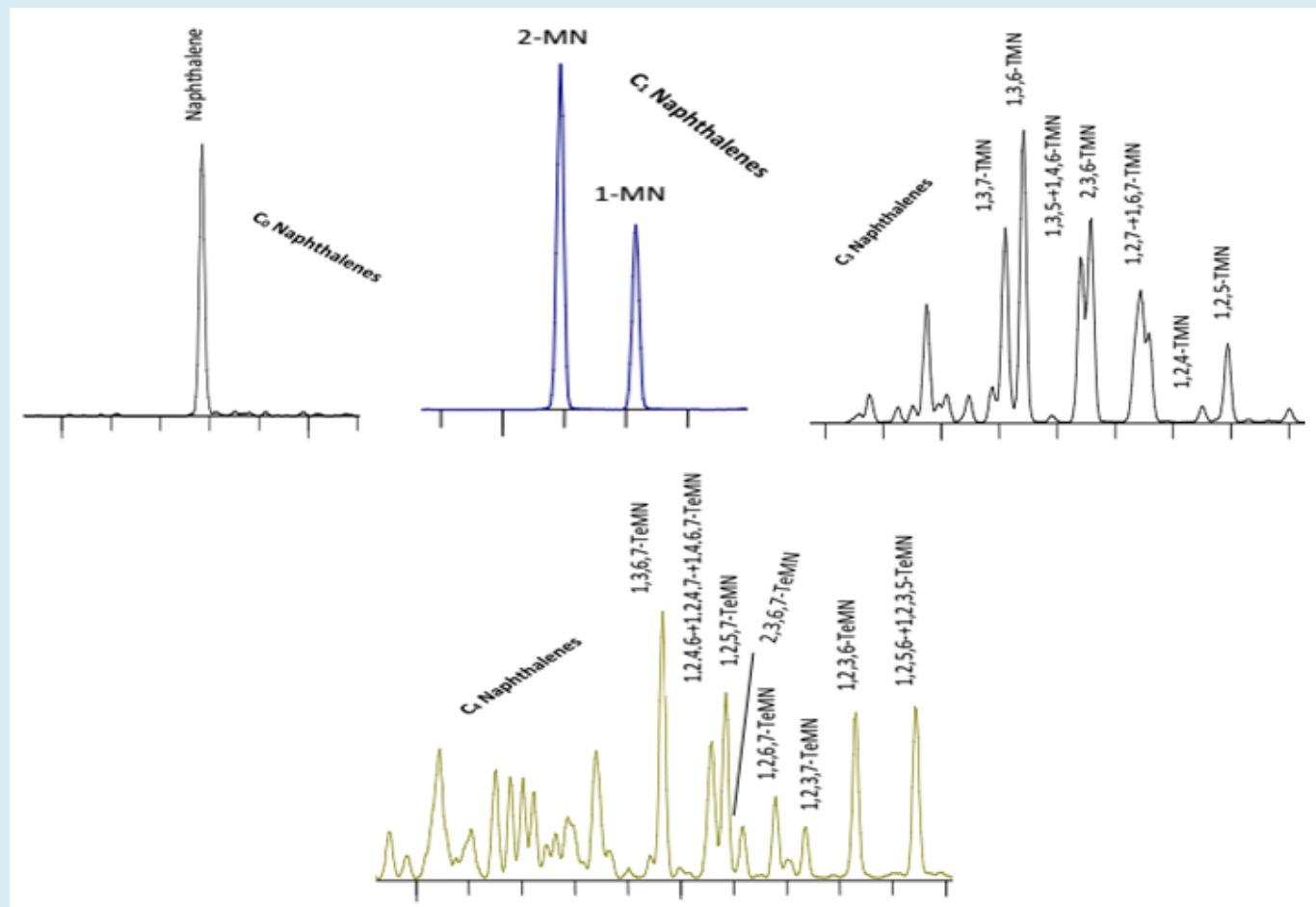

Figure 2: Representative mass fragmentograms showing the distribution of $\mathrm{C}_{0}-\mathrm{C}_{4}$ Naphthalenes in the crude oil (sample $\mathrm{B}$ ) at $\mathrm{m} / \mathrm{z} 128,142,156,170$ and 184 .

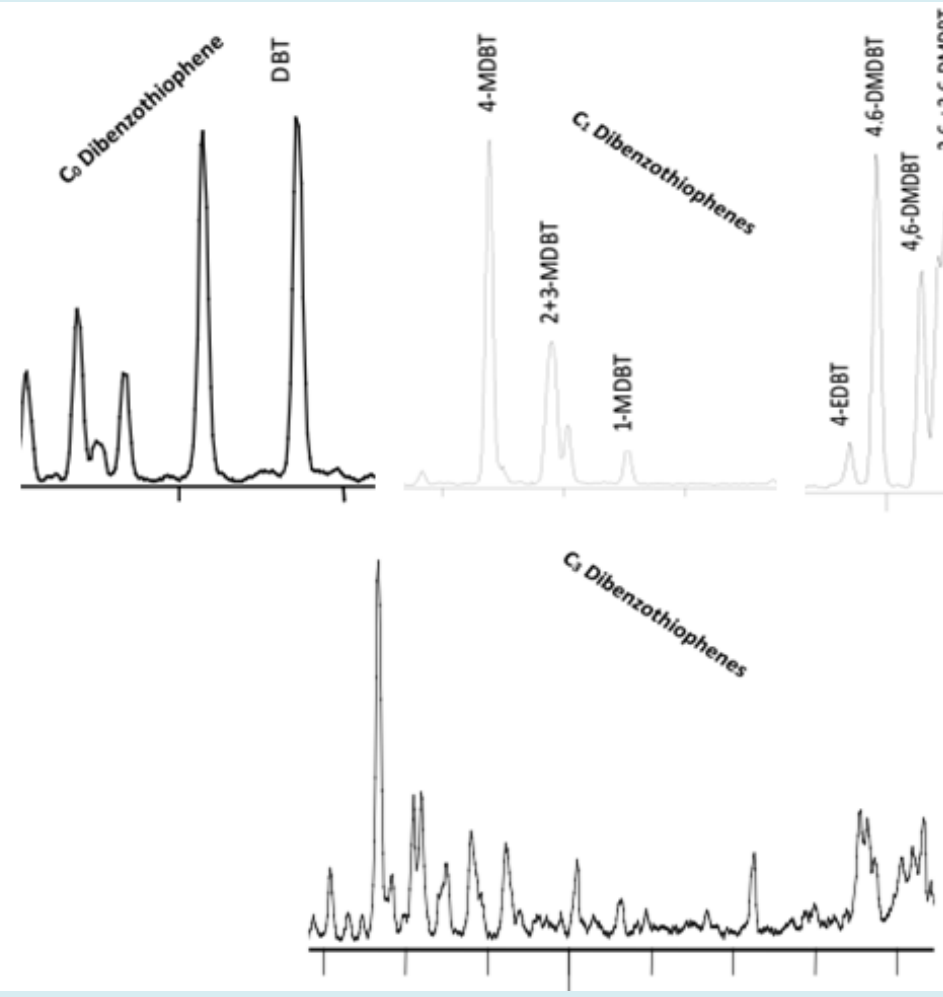

Figure 3: Representative mass fragmentograms showing the distribution of $\mathrm{C}_{0}-\mathrm{C}_{3}$ dibenzothiophenes in the crude oil (sample B) at $\mathrm{m} / \mathrm{z}$ 184, 198, 212 and 226. 

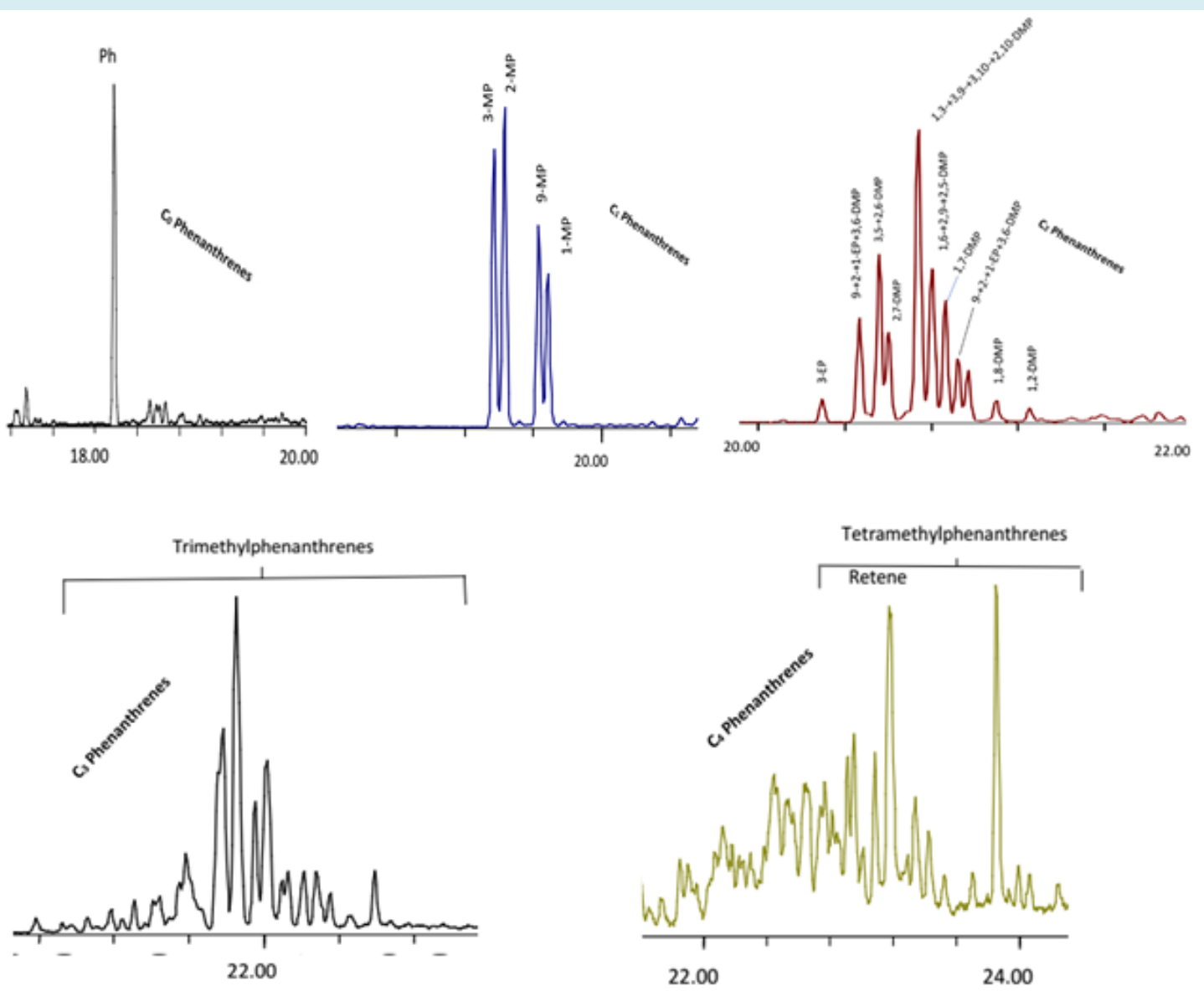

Figure 4: Representative mass fragmentograms showing the distribution of $\mathrm{C}_{0}-\mathrm{C}_{4}$ Phenanthrenes in the crude oil (sample $\mathrm{B}$ ) at $\mathrm{m} / \mathrm{z} 178,192,206,220$ and 234 .

\begin{tabular}{|c|c|}
\hline Peaks & Compound \\
\hline BP & Biphenyl \\
\hline $2-$ MBP & 2-Methylbiphenyl \\
\hline DPM & Diphenylmethyl \\
\hline $3-$ MBP & 3-Methylbiphenyl \\
\hline $4-$ MBP & 4-Methylbiphenyl \\
\hline DBF & Dibenzofuran \\
\hline DBT & Dibenzothiophene \\
\hline $4-$ MDBT & 4-Methyl Dibenzothiophene \\
\hline $2+3-M D B T$ & 2 \&-Methyl Dibenzothiophene \\
\hline 1-MDBT & 1-Methyl Dibenzothiophene \\
\hline $4-$-EDBT & 4-Ethyl Dibenzothiophene \\
\hline $4,6-$ DMDBT & 4,6-Dimethyl Dibenzothiophene \\
\hline $2,4-$ DMDBT & 2,4-Dimethyl Dibenzothiophene \\
\hline $2,6+3,6-D M D B T$ & 2,6 \& 3,6-Dimethy Dibenzothiophene \\
\hline
\end{tabular}




\section{Petroleum \& Petrochemical Engineering Journal}

\begin{tabular}{|c|c|}
\hline 3,7-DMDBT & 3,7-Dimethyl Dibenzothiophene \\
\hline 1,4-+1,6-+1,8-DMDBT & $(1,4+1,6+1,8)$-Dimethyl Dibenzothiophene \\
\hline 1,2+1,9-DMDBT & 1,2 \& 1,9-Dimethyl Dibenzothiophene \\
\hline $\mathrm{N}$ & Naphthalene \\
\hline 2-MN & 2-Methylnaphthalene \\
\hline 1-MN & 1-Methylnaphthalene \\
\hline 2-EN & 2-Ethylnaphthalene \\
\hline 1-EN & 1-Ethylnaphthalene \\
\hline 2,6-+2,7-DMN & 2,6 \& 2,7-Dimethylnaphthalene \\
\hline $1,3+1,7-\mathrm{DMN}$ & 1,3 \& 1,7-Dimethylnaphthalene \\
\hline 1,6-DMN & 1,6-Dimethylnaphthalene \\
\hline 1,4-+2,3-DMN & 1,4 \& 2,3-Dimethylnaphthalene \\
\hline 1,5-DMN & 1,5-Dimethylnaphthalene \\
\hline 1,2-DMN & 1,2-Dimethylnaphthalene \\
\hline 1,3,7-TMN & 1,3,7-Trimethylnaphthalene \\
\hline 1,3,6-TMN & 1,3,6-Trimethylnaphthalene \\
\hline $1,3,5+1,4,6-\mathrm{TMN}$ & $(1,3,5 \& 1,4,6)$-Timethylnaphthalene \\
\hline 2,5,6-TMN & 2,5,6-Trimethylnapthalene \\
\hline 1,2,7-+1,6,7-TMN & $(1,2,7 \& 1,6,7)$-Trimethylnaphthalene \\
\hline 1,2,4-TMN & 1,2,4-Trimethylnaphthalene \\
\hline $1,2,5-\mathrm{TMN}$ & 1,2,5-Trimethylnaphthalene \\
\hline 1,3,6,7-TeMN & 1,3,6,7-Tetramethylnaphthalene \\
\hline $1,2,4,6-+1,2,4,7-+1,4,6,7-\mathrm{TeMN}$ & $\begin{array}{c}(1,2,4,5+1,2,4,7+1,4,6,7)-T e t r a m e t h y l- \\
\text { naphthalene }\end{array}$ \\
\hline 1,2,5,7-TeMN & 1,2,5,7-Tetramethylnaphthalene \\
\hline 2,3,6,7-TeMN & 2,3,6,7-Tetramethylnaphthalene \\
\hline 1,2,6,7-TeMN & 1,2,6,7-Tetramethylnaphthalene \\
\hline 1,2,3,7-TeMN & 1,2,3,7-Tetramethylnaphthalene \\
\hline 1,2,3,6-TeMN & 1,2,3,6-Tetramethylnaphthalene \\
\hline $1,2,5,6+1,2,3,5-\mathrm{TeMN}$ & $(1,2,5,6 \& 1,2,3,5)$-Tetramethylnaphthalene \\
\hline $\mathrm{P}$ & Phenanthrene \\
\hline 3-MP & 3-Methylphenanthrene \\
\hline 2-MP & 2-Methylphenanthrene \\
\hline 9-MP & 9-Methylphenanthrene \\
\hline 1-MP & 1-Methylphenanthrene \\
\hline 3-EP & 3Ethylphenanthrene \\
\hline $9+2-+1-\mathrm{EP}+3,6-\mathrm{DMP}$ & $(9+2+1$-EP $+3,6)$-Dimethylphenanthrene \\
\hline 3,5-+2,6-DMP & $(3,5 \& 2,6)$-Dimethylphenanthrene \\
\hline 2,7-DMP & 2,7-Dimethylphenanthrene \\
\hline $1,3-+3,9-+3,10-+2,10-\mathrm{DMP}$ & $\begin{array}{c}(1,3+3,9+3,10+2,10) \text {-Dimethylphenan- } \\
\text { threne }\end{array}$ \\
\hline
\end{tabular}




\section{Petroleum \& Petrochemical Engineering Journal}

\begin{tabular}{|c|c|}
\hline $1,6+2,9+2,5-\mathrm{DMP}$ & $(1,6+2,9+2,5)$-Dimethylphenanthrene \\
\hline $1,7-\mathrm{DMP}$ & $1,7-$ Dimethylphenanthrene \\
\hline $2,3-+1,9-+4,9-+4,10-\mathrm{DMP}$ & $\begin{array}{c}(2,3+1,9+4,9+4,10) \text {-Dimethylphenan- } \\
\text { threne }\end{array}$ \\
\hline $1,8-\mathrm{DMP}$ & 1,8 -Dimethylphenanthrene \\
\hline $1,2-\mathrm{DMP}$ & 1,2 -Dimethylphenanthrene \\
\hline
\end{tabular}

Table 1: Peak Identification of Some Polycyclic Aromatic Hydrocarbons and Aromatic Sulfur Compounds (Thiophenes) in the Niger Delta Crude Oils.

Generally,variationsinrelativedistributionofgeochemical compounds indicate a difference in source and depositional environment of organic matter [14,15].Aromatichydrocarbon plant markers such as 1,2,5-trimethylnaphthalene $(1,2,5-$ TMN), 1-methylphenanthrene, 1,7-dimethylphenanthrene and retene, derived from Araucariaceae [16], are all present in crude oil samples $A$ and $F$. The relative abundance of $1,2,5-\mathrm{TMN}$ among the naphthalenes in samples A (6.33\%) and $\mathrm{F}(6.16 \%)$ support significant angiosperm higher plant input to the source rock that generated the oils, which was more in sample A. This feature was retained in their compositional mixes. These data are consistent with the presence of oleanane and/or lupane in the Niger Delta crude oils. Furthermore, log ratios of (1-MP/9-MP), (1,7-DMP/1,3$+3,9-+2,10-+3,10-\mathrm{DMP})$ and (retene/9-MP) were proposed as a means of detecting organic matter input from coniferous higher plants [17]. These source specific aromatic ratios did not exceed the thresholds for samples $\mathrm{A}, \mathrm{F}$ and their mixtures. Their source organic matter however, is consistent with the aliphatic hydrocarbon data for these sets of crude oils which suggested greater higher plant organic matter input as reported by Onyema et al. [12].

Most of the maturity parameters computed for the individual crude oils and their compositional mixtures (Table 2) revealed an increase in thermal maturity from sample $A$ to F. Radke [6] established that aromatic hydrocarbons do change in a regular fashion with increasing maturity, thus a number of maturity parameters have been developed based on the distributions of alkyl naphthalene, biphenyl, dibenzothiophene and phenanthrene. Maturity parameters computed from these aromatic hydrocarbon compounds in the oil samples and their mixtures are presented in Table 2.

\begin{tabular}{|c|c|c|c|c|c|c|c|}
\hline \multirow{2}{*}{ S.No. } & Diagnostic Ratio & \multicolumn{5}{|c|}{ Samples } \\
\cline { 3 - 8 } & MNR & A & B & C & D & E & F \\
\hline 1 & DNR & 1.44 & 1.45 & 1.79 & 1.45 & 1.84 & 1.2 \\
\hline 2 & TNR-1 & 6.66 & 6.86 & 9.8 & 3.9 & 10.99 & 9.43 \\
\hline 3 & TNR-2 & 0.84 & 1.1 & 1.15 & 1.11 & 1.3 & 1.47 \\
\hline 4 & TNR-3 & 0.74 & 0.86 & 0.82 & 0.83 & 0.94 & 0.98 \\
\hline 5 & $\log 1,2,7$ TMN/1,3,7-TMN & 0.53 & 0.58 & 0.6 & 0.58 & 0.72 & 0.71 \\
\hline 6 & TMNr & 0.15 & 0.08 & 0.11 & 0.09 & 0.12 & 0.13 \\
\hline 7 & Rcb & 0.53 & 0.58 & 0.6 & 0.58 & 0.72 & 0.71 \\
\hline 8 & MPI & 0.84 & 0.91 & 0.89 & 0.9 & 0.96 & 0.99 \\
\hline 9 & MPI-2 & 0.87 & 1.25 & 1.02 & 1.05 & 1.04 & 1.02 \\
\hline 10 & MPI-3: & 0.85 & 1.29 & 1.05 & 1.1 & 1.07 & 1.06 \\
\hline 11 & Rc & 1.09 & 0.66 & 1.54 & 1.54 & 1.61 & 1.61 \\
\hline 12 & MPDF & 0.92 & 1.15 & 1.01 & 1.03 & 1.02 & 1.01 \\
\hline 13 & DPR & 0.52 & 0.59 & 0.61 & 0.61 & 0.62 & 0.62 \\
\hline 14 & MBpR & 0.36 & 0.45 & 0.15 & 0.48 & 0.48 & 0.48 \\
\hline 15 & P/MP & 0.42 & 0.5 & 0.5 & 0.47 & 0.51 & 0.52 \\
\hline 16 & & & &
\end{tabular}


Petroleum \& Petrochemical Engineering Journal

\begin{tabular}{|c|c|c|c|c|c|c|c|}
\hline 17 & MDR & 2.33 & 5.47 & 7.42 & 6.41 & 9.17 & 7.45 \\
\hline 18 & MDR* $^{*}$ & 0.69 & 0.85 & 0.88 & 0.87 & 0.9 & 0.9 \\
\hline 19 & Rcs & 0.68 & 0.91 & 1.05 & 0.98 & 1.12 & 1.05 \\
\hline 20 & DBT/P & 0.18 & 0.09 & 0.1 & 0.09 & 0.1 & 0.08 \\
\hline 21 & $\log (1-\mathrm{MP} / 9-\mathrm{MP})$ & -0.11 & -0.13 & -0.13 & -0.12 & -0.12 & -0.13 \\
\hline 22 & $\log ($ Retene/9-MP) & -0.38 & -0.76 & -0.78 & -0.88 & -0.96 & -1.35 \\
\hline 23 & $\log (1,7-\mathrm{MPP} /[1,3+3,9+2,10+3,10-\mathrm{SMP}])$ & -0.26 & -0.39 & -0.41 & -0.42 & -0.45 & -0.45 \\
\hline
\end{tabular}

Table 2: Aromatic hydrocarbon thermal maturity parameters for two Niger Delta crude oils and their compositional mixtures. MNR: methylnaphthalene ratio (2-MN/1-MN)

DNR-1: dimethylnaphthalene ratio $1([2,6-+2,7-\mathrm{DMN}] / 1,5-\mathrm{DMN})$

TNR-1: trimethylnaphthalene ratio $1(2,3,6-\mathrm{TMN} /[1,4,6-+1,3,5-\mathrm{TMN}])$

TNR-2: trimethylnaphthalene ratio $2(2,3,6-+1,3,7-\mathrm{TMN} /[1,4,6-+1,3,5-+1,3,6-\mathrm{TMN}])$

TMNr: trimethylnaphthalene ratio (1,3,7-TMN/[1,3,7-TMN + 1,2,5-TMN])

TeMNr: tetramethylnaphthalene ratio $(1,3,6,7-\mathrm{TeMN} /[1,3,6,7-+1,2,5,6-\mathrm{TeMN}])$

MPI: methylphenanthrene index 1.5 $\cdot[3-\mathrm{MP}+2-\mathrm{MP}] /[\mathrm{P}+9-\mathrm{MP}+1-\mathrm{MP}]$

MPI-2: methylphenanthrene index 2 (3* 2-MPI (P+ I-MP + 9-MP)

MPI-3: Methylphenanthrene Index

Rc: calculated reflectance $(0.6 \cdot \mathrm{MPI}+0.4)$

$R c b: 0.40+0.6 \times(\mathrm{TNR}-2)$

Rcs: $0.073 \times \mathrm{MDR}+0.5$

MPDF: methylphenanthrene distribution fraction ([3-MP + 2-MP]/RMPs)

DPR: dimethylphenanthrene ratio ([3,5- + 2,6-DMP + 2,7-DMP]/[1,3 + 3,9- + 2,10- + 3,10-DMP + 1,6- + 2,9- + 2,5-DMP])

MBpR: methylbiphenyl ratio (3-MBp/2-MBp)

DBT/P: Dibenzothiophene/Phenanthrene

DMBpR-x: dimethylbiphenyl ratio x (3,5-DMBp/2,5-DMBp)

DMBpR-y: dimethylbiphenyl ratio y (3,30-DMBp/2,30-DMBp)

MDR: methyldibenzothiophene ratio (4-MDBT/1-MDBT)

MDR*: Methyldibenzothiophene ratio (4-MDBT/4-DBT + 1-MDBT)

DMDR: dimethyldibenzothiophene ratio (4,6-DMDBT/[3,6- + 2,6-DMDBT])

Dimethylnaphthalene ratio (DNR-1) is a useful aromatic hydrocarbon maturity parameter for samples having mean vitrinite reflectance $(R)$ equal or higher than $1 \%$. Generally, ratios of DNR-1 > 6.65 (Table 2) suggest that thermal maturity of the two Niger Delta crude oils, samples A and F, reached peak to late oil generation window. The result also reveal that the DNR-1 feature of the two Niger Delta crude oils was expressed in their mixtures, except for sample D with a low ratio of 3.90, but was not relative to the compositional mix. The methylnaphthalene ratio (MNR) as shown on Table 2 does not support the maturity sequence exhibited by other alkynaphthalene thermal maturity parameters. The relative maturities based on MNR appear spurious when compared to other maturity indices as it lacked sufficient variation to distinguish maturity differences in the crude oils. No peculiar trend could be deduced for the MNR ratio which ranges from $1.20-1.84$ for both the individual and composition mix crude oil samples. It therefore showed a weak to moderate correlation between the individual crude oils and its commingled samples.
The methylphenanthrene index (MPI) is a commonly used thermal maturity parameter of aromatic hydrocarbons which is calibrated with mean vitrinite reflectance $\left(R_{m}\right)$ for source rocks and crude oils [18]. The calculated vitrinite reflectance $\left(R_{c}\right)$ from MPI classifies crude oils thermal maturity into immature $(0.70)$, mature $(0.85)$ and post mature ( $>0.95$ ) [19]. The MPI and $R_{c}$ for the crude oil samples range from 0.87 to 1.25 and 0.92 to 1.15 respectively. These show high maturity of the source rocks which generated the two Niger Delta crude oils with sample A oil (Rivers state) being slightly less mature than sample $\mathrm{F}$ oil (Delta state). The maturity sequence however does not show a linear relationship to the compositional mix of the two Niger Delta crude oils. Methyldibenzothiophene ratio (MDR; 4-/1-MDBT) is sensitive to maturity changes and shows good correlation with vitrinite reflectance [20]. The commonly used parameter, methyldibenzothiophene ratio (MDR), is derived based on a methyl shift from thermally less stable isomer (1-MDBT) to thermally more stable isomer (4-MDBT) with increase in thermal maturity. MDR is calibrated with vitrinite reflectance and reported as $R_{c s}$. The MDR and $R_{c s}$ values for 
oil samples $A$ and $F$ and their mixtures, samples $\mathrm{C}-\mathrm{E}$, ranged from 2.33 to 9.17 and 0.68 to 1.12 respectively. This suggest a peak to late oil generation window thermal maturity of the two Niger Delta crude oils. MDR and $\mathrm{R}_{\mathrm{cs}}$ showed a linear relationship between the two Niger Delta crude oils and their compositional mix. Variations in expulsion stages of 1-MDBT and 4-MDBT isomers from kerogen was shown to affect MDR and Chakhmakhchev and Suzuki [20] have pointed out its limitations for coal samples where it does not show linear relationship between 0.5 to $1.0 \% \mathrm{R}_{\text {cs }}$. However, Radke et al. [7] introduced a revised form of MDR as MDR* where it was calculated by traditional biomarker maturity parameters i.e. 4-MDBT/(4-MDBT + 1-MDBT). MDR* values shown in Table 2 range from $0.68-1.05$ and reveal higher thermal maturity for sample F. The distribution of methylbiphenyl represented in the methylbiphenyl ratio (MBpR) further validates other maturity parameters which suggest a lower maturity for sample A compared to sample F. The calculated maturity parameter results reveal the two Niger Delta crude oils were of high maturity with the crude oil from Delta State (sample F) being of more matured than Rivers State (sample A).

TNR-1 values $>1$ for all the samples except sample A indicates that the maturity of source rocks generating these oils reached post mature level. This parameter exhibited a strong correlation between the individual crude oil samples and their composition mixtures. Similarly, TNR-2 a useful aromatic hydrocarbon thermal maturity parameter showed trend with increase in thermal maturity of the crude oil samples and their mixtures (Figure 5).

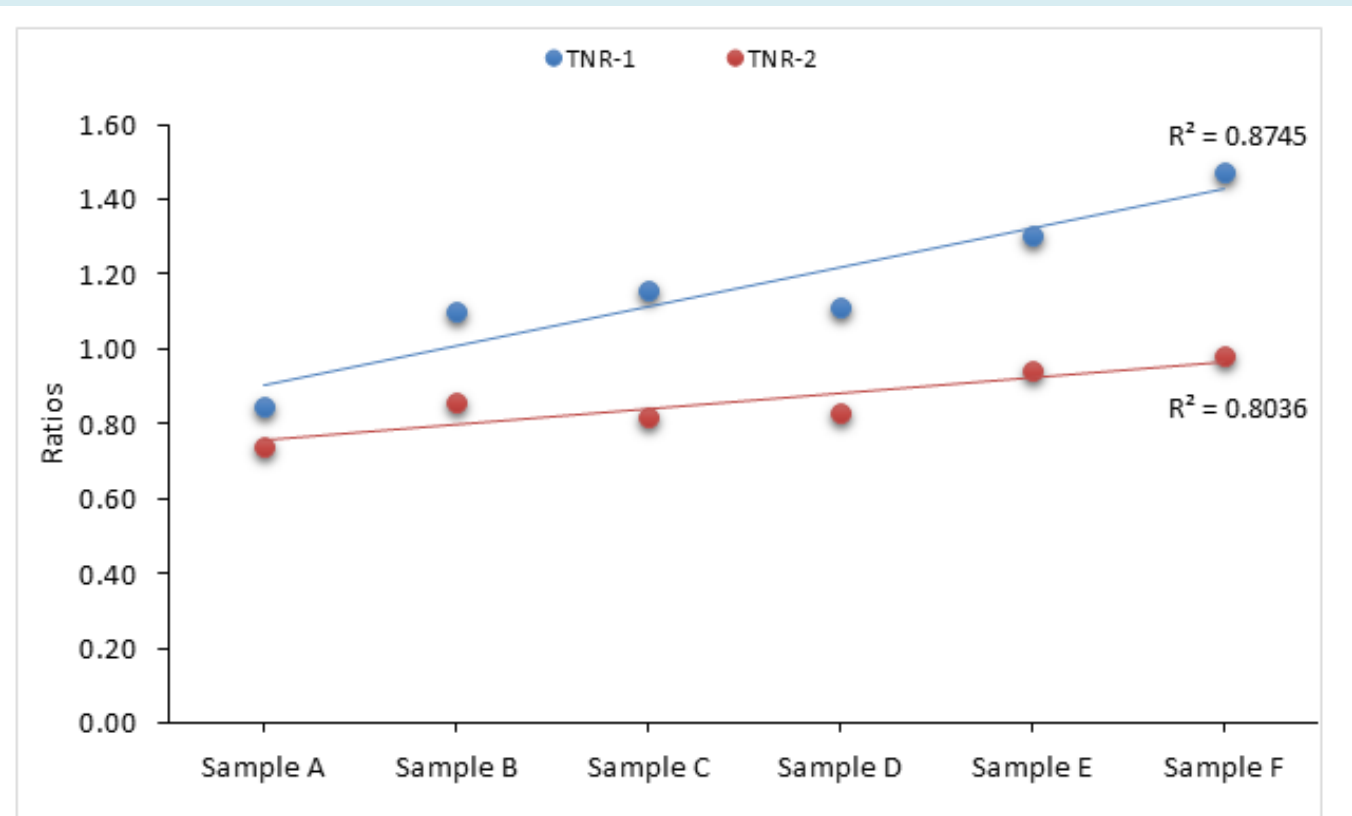

Figure 5: Plot of trimethylnaphthalene ratios (TNR-1 and TNR-2) against the studied crude oils and their compositional mixtures showing the level of correlation.

TNR-2 values $(0.74-0.98)$ and the calculated vitrinite reflectance $R_{c b}(0.84-0.99)$ indicate that the thermal maturities of the crude oils reached peak to late oil generation window. The values further showed sample $\mathrm{F}$ to be more matured than sample A [21]. In addition, the maturity sequence in the individual samples were expressed in their mixtures and showed a very strong linear relationship (0.8045) with the compositional mix as shown in Figure 5.

\section{Conclusions}

Crude oil samples from Rivers and Delta states of the Niger Delta exhibited a significant range of thermal maturities reflecting different timing of oil generation and expulsion from their source rocks. Aromatic hydrocarbon maturity results revealed that the two Niger Delta crude oils were of high maturity state as reflected in the maturity parameters. The thermal maturity of the crude oil from Delta State (sample F) was higher than that from Rivers State (sample A) in all the parameters evaluated. All alkyl naphthalene thermal maturity parameters suggest a peak to late oil generation window for the crude oil samples except methylnaphthalene ratio (MNR) whose maturity sequence lacks sufficient variation to distinguish maturity differences 


\section{Petroleum \& Petrochemical Engineering Journal}

in the crude oils. All the maturity parameters evaluated showed weak to moderate correlation $\left(R^{2}\right)$ between the two Niger Delta crude oils and their composition mixtures, except TRI-1 and TRI-2 whose maturity character in the oils and their mixtures showed a strong correlation.

\section{References}

1. Didyk BM, Simoneit BRT, Brassell SC, Eglinton G (1978) Organic geochemical indicators of palaeoenvironmental conditions of sedimentation. Nature 272: 216-222.

2. Onyema MO, Manilla PN (2010) Light hydrocarbon correlation of Niger Delta crude oils. Journal of American Science 6(6): 82-88.

3. Ahmed M, Oliver L, Fuentes D, Meinhold G (2013) Origin of oil and bitumen in the Late Devonian Siljan impact structure, Central Sweden. Org Geochem 68: 13-26.

4. Farrimond P, Taylor A, Telnaes N (1998) Biomarker maturity parameters: the role of generation and thermal degradation. Org Geochem 29(5-7): 1181-1197.

5. Okoroh NC, Onyema MO, Osuji LC (2018) Compositional significance of phenanthrenes for geochemical correlation of two commingled Niger Delta crude oils. Pet Coal 60(6): 1328-1335.

6. Radke M (1988) Application of aromatic compounds as maturity indicators in source rocks and crude oils. Mar Pet Geol 5(3): 224-236.

7. Radke M, Welte DH, Willsch H (1986) Maturity parameters based on aromatic hydrocarbons: influence of organic matter type. Org Geochem 10(1-3): 51-63.

8. Chakhmakhchev A, Suzuki N (1995) Saturate biomarkers and aromatic sulfur compounds in oils and condensate from different source rock lithologies of Kazakhstan, Japan and Russia. Org Geochem 23(4): 289-299.

9. Hegazi AH, Andersso JT, El-gayar MS (2003) Application of gas chromatography with atomic emission detection to the geochemical investigation of polycyclic aromatic sulfur heterocycles in Egyptian crude oils. Fuel Process Technol 85(1): 1-19.

10. Van Aarssen BGK, Bastow TP, Alexander R, Kagi RI (1999) Distribution of methylated naphthalenes in crude oils: indicators of maturity, biodegradation and mixing. Org Geochem 30(10): 1213-1227.

11. Sonibare O, Alimi H, Jarvie D, Ehinola OA (2008) Origin and occurrence of crude oil in the Niger Delta, Nigeria. Journal of Pet Sc and Eng 61(2-4): 99-107.

12. Onyema MO, Okoroh NC, Okorie IH, Osuji LC (2018) Geochemical characterization of two Niger Delta crude oils and their mixtures I: Bulk properties and aliphatic hydrocarbon distributions. Modern Chemistry 6(3): 3943.

13. Manilla PN, Onyema OM (2008) Correlation of some crude oils using low molecular weight geochemical markers: A case study of the Niger Delta. Journal of Chem Soc of Nig 33: 225-234.

14. Volk H, George SC, Middleton H, Schofield S (2005) Geochemical comparison of fluid inclusion and presentday oil accumulations in the Papuan Forland-Evidence for previously unrecognised petroleum source rocks. Organic Geochemistry 36(1): 29-51.

15. Onyema MO, Osuji LC (2015) Gas chromatography mass spectrometry (GC-MS) compositional analyses of aromatic hydrocarbons in Niger Delta crude oils. Pet Coal 57(5): 526-531.

16. Alexander R, Kagi RI, Rowland SJ, Sheppard PN, Chirila TV (1985) The effects of thermal maturity on distributions of dimethylnapthelenes and trimethylnaphthelene in some ancient sediments and petroleums. Geochim Cosmochim Acta 49(2): 385-395.

17. Strachan MG, Alexander R, Kagi R (1988) Trimethylnaphthalenes in crude oils and sediments: effect of source and maturity. Geochim Cosmochim Acta 52(5): 1255-1264.

18. Xiaowen G, Sheng H (2009) Aromatic hydrocarbons as indicators of origin and maturation for light oils from Panyu Lower Uplift in Pearl River Mouth Basin. Journal of Earth Science 20(5): 824-835.

19. Preston JC, Edwards DS (2000) The petroleum geochemistry of oils and source rocks from the northern Bonaparte Basin, offshore northern Australia. The Australian Petroleum Production and Exploration Journal 40(1): 257-282.

20. Chakhmakhchev A, Suzuki N (1997) Distribution of alkylated dibenzothiophenes in petroleum as a tool for maturity assessments. Org Geochem 26(7-8): 483-490.

21. Schoell M (1984) Recent advances in petroleum isotope geochemistry. Org Geochem 6: 645-663. 